\title{
Correction to: Preparation, characterization of novel poly(hydroxybutyrate)/poly(butylene succinate)/ZnO porous resin and application in groundwater purification
}

\author{
M. M. El-Toony ${ }^{1} \cdot$ Gh. Eid $^{2} \cdot$ S. A. Asiri ${ }^{1} \cdot$ H. M. Algarni ${ }^{3}$
}

Published online: 9 October 2019

(C) Islamic Azad University (IAU) 2019

\section{Correction to: International Journal of Environmental Science and Technology \\ https://doi.org/10.1007/s13762-019-02421-4}

The article listed above was initially published with incorrect Acknowledgements. In this correction, new Acknowledgements are given below.

Acknowledgements The authors extend their appreciation to the Deanship of Scientific Research at King Khalid University for funding this work through Group Research Project under Grant Number (R.G.P.1/35/38).

Publisher's Note Springer Nature remains neutral with regard to jurisdictional claims in published maps and institutional affiliations.

The original article can be found online at https://doi.org/10.1007/ s13762-019-02421-4.

M. M. El-Toony

malnoni@kku.edu.sa; toonyoptrade@yahoo.com

1 Chemistry Department, Faculty of Science and Art, Tehama

Branch, King Khalid University, Abha, Saudi Arabia

2 Physics Department, Faculty of Science and Art, Tehama

Branch, King Khalid University, Abha, Saudi Arabia

3 King Khalid University, Abha, Saudi Arabia 